\section{Mudança na graduação das profissões de saúde sob o eixo da integralidade}

\author{
Changes in undergraduate education \\ in the health professions from the perspective \\ of comprehensive training
}

Ricardo Burg Ceccim 1,2

Laura C. Macruz Feuerwerker 2

\title{
Introdução
}

1 Programa de Pós-graduação em Educação, Universidade Federal do Rio Grande do Sul, Porto Alegre, Brasil.

2 Departamento de Gestão da Educação na Saúde, Ministério da Saúde. Brasília, Brasil.

Correspondência R. B. Ceccim

Programa de Pós-graduação em Educação, Universidade Federal do Rio Grande do Sul. Rua Dr. Raul Moreira 550, Porto Alegre, RS 90820-160, Brasil. ceccim@edu.ufrgs.br

\section{Abstract}

This article discusses the issue of legal, technical, and political legitimacy for formulating $a$ public policy aimed at organizing the training of health professionals in accordance with the population's health needs, while highlighting the competencies of the education and health sectors in this construction. Comprehensiveness is viewed as the main thrust for proposing and supporting the changes needed in the training of professionals in education and health, since it involves an expanded understanding of health, the linkage among multi-professional and interdisciplinary knowledge and practices, and dialogue/exchange with health system users, aimed at innovation of practices in all scenarios of health care and health sector management.

Comprehensive Health Care; Professional Practice; Health Policy
Podemos pensar o presente artigo como uma evocação, uma vez que não se ocupará de revisar a literatura ou cotejar autores na sustentação de um posicionamento. Nessa medida, apresenta-se mais como um ensaio do que uma analítica do campo, buscando formular uma compreensão e/ou uma interpretação das designações políticas da reforma sanitária brasileira ao campo da formação no Sistema Único de Saúde (SUS). Uma das áreas menos problematizadas até hoje na formulação de políticas do SUS é a da formação. Sempre referido, criticado e crivado de proposições espontâneas, o campo carece de formulações construídas intelectualmente desde a gestão em saúde, essas operadas quase sempre desde as propostas conteúdo-curriculares. De outro lado, na educação, como setor específico das políticas públicas, não se observa a discussão da docência e do ensino-aprendizagem orientado para as profissões de saúde.

A evocação trazida, então, busca configurar uma análise da integralidade da atenção à saúde como eixo norteador da necessidade de mudança na formação dos profissionais dessa área de conhecimento e contribuir à formulação de uma política do SUS para a mudança na graduação das profissões de saúde.

A Constituição Nacional 1 firmou que as ações e os serviços de saúde, ao se constituírem por um sistema único, integram uma rede que 
deve ser organizada segundo três diretrizes, uma delas o atendimento integral, ou seja, a integralidade da atenção surge como princípio constitucional norteador da formulação de políticas de saúde. Especificamente em relação aos trabalhadores para esse setor, vamos encontrar na Constituição Nacional que cabe ao SUS ordenar a formação de recursos humanos na área de saúde. Na Lei Orgânica da Saúde, o título relativo aos recursos humanos assevera que a política para os trabalhadores da área deve cumprir o objetivo de organizar um sistema de formação em todos os níveis de ensino, inclusive de pósgraduação, além de programas de permanente aperfeiçoamento de pessoal. O sistema educacional não fica fora do ordenamento da formação ou da organização do sistema de formação pelo fato de ser esse o setor que detém os instrumentos de gestão e a legitimidade de regulação da educação nacional. Entretanto, as funções sociais do ordenamento, controle, fiscalização, auditoria e avaliação são função de Estado e ganham características próprias no setor da saúde. Essas funções estão sob outro princípio norteador das políticas públicas, o controle social (participação popular com poder decisório, regulamentada por Lei específica). Os dois setores saúde e educação, pela legitimidade e legalidade, ora de um, ora de outro, devem ocupar-se das funções de regulação de Estado no tocante à formação na área da saúde (credenciamento, descredenciamento, recredenciamento de cursos, programas e escolas de formação; elevação da capacidade educativa dos mesmos; observação do cumprimento das funções públicas de formação das novas gerações profissionais; melhoria das condições de ensino-aprendizagem; estruturação de processos de avaliação institucional, externa e interna e ações de transformação institucional) e submeter as principais decisões políticas à participação popular.

Não como artifício ou demagogia, a participação popular deve assegurar a mais ampla permeabilidade da atenção e da formação em saúde às necessidades dos usuários. As necessidades dos usuários das ações e serviços de saúde passam à condição de direito, seja porque como pessoas, todos temos o direito de sermos atendidos conforme nossas necessidades, seja porque este é o objeto da saúde: assegurar plena atenção às necessidades das pessoas. Toda a regulação relativa à saúde deveria ser usuário-centrada, em última instância, único motivo para ordenar serviços de atenção e instituições de formação de profissionais.
Se a integralidade da atenção deve ser um princípio norteador da formulação de políticas de saúde e a formação para a área de saúde deve ser uma política do SUS, cabe perguntar-nos sobre a integralidade da atenção à saúde e a formação dos profissionais. Voltando às três diretrizes ordenadoras do SUS, encontramos o $d e$ safio da descentralização da gestão com comando único por esfera de governo, princípio norteador claramente identificado com os valores de gerenciamento e condução articulada pelas diferentes esferas de governo. Depois, o desafio da participação popular, já referido, dirigido, sem qualquer dúvida, à garantia da atuação ativa da sociedade na tomada de decisões políticas e no acompanhamento do desempenho do sistema de saúde. Por fim, o desafio do atendimento integral, com prioridade para as atividades preventivas, sem prejuízo dos serviços assistenciais. A integralidade da atenção, então, deve informar o campo das práticas e o de uma formação que dê possibilidade a essas práticas. Fechase um roteiro em que cada diretriz deveria interrogar as demais em busca da unicidade do sistema, sem postergar responsabilidades.

Nossa intenção é a de problematizar a integralidade da atenção como questão à formação dos profissionais de saúde, recuperando a tarefa constitucional designada pela reforma sanitária brasileira de formular políticas de formação para a área da saúde. Nossa intenção também é a de interpretar essa formulação de políticas sem sobreposição, exceto pela ação intencionalmente intersetorial, às tarefas do setor da educação. Se não cabe ao setor da saúde o disciplinamento da educação por meio do ensino em instituições educacionais, cabe-lhe contribuir para que a educação se vincule ao mundo do trabalho e às práticas sociais em saúde, como determina a Constituição Nacional ao setor da educação, e para que esse setor cumpra a sua finalidade constitucional de desenvolvimento pleno dos educandos, seu preparo para o exercício da cidadania e sua qualificação para o trabalho 1,2 .

Se o dever de Estado para com a saúde afirma como atribuição do SUS o ordenamento da formação para a área, esse deve interferir pela orientação da formação em coerência com as diretrizes constitucionais da saúde. A própria legislação infraconstitucional determina o cumprimento do objetivo de contribuir para a organização de um sistema de formação em todos os níveis de ensino e, ainda, a constituição dos serviços públicos que integram o SUS co- 
mo campos de prática para o ensino e a pesquisa, mediante normas específicas, elaboradas conjuntamente com o sistema educacional 1,3 . O dever de Estado para com a educação afirma como atribuição do sistema educacional nacional a garantia dos padrões de qualidade do ensino, a vinculação entre a formação, o trabalho e as práticas sociais e, ainda, a integração das ações do poder público que conduzam à melhoria da qualidade do ensino, à formação para o trabalho e à promoção humanística, científica e tecnológica do país 1,2 .

\section{A integralidade da atenção à saúde e as previsões em lei para as políticas públicas de educação e de saúde}

Podemos dizer que há consenso entre os críticos da educação dos profissionais de saúde em relação ao fato de ser hegemônica a abordagem biologicista, medicalizante e procedimento-centrada. O modelo pedagógico hegemônico de ensino é centrado em conteúdos, organizado de maneira compartimentada e isolada, fragmentando os indivíduos em especialidades da clínica, dissociando conhecimentos das áreas básicas e conhecimentos da área clínica, centrando as oportunidades de aprendizagem da clínica no hospital universitário, adotando sistemas de avaliação cognitiva por acumulação de informação técnico-científica padronizada, incentivando a precoce especialização, perpetuando modelos tradicionais de prática em saúde. Na abordagem clássica da formação em saúde, o ensino é tecnicista e preocupado com a sofisticação dos procedimentos e do conhecimento dos equipamentos auxiliares do diagnóstico, tratamento e cuidado, planejado segundo o referencial técnico-científico acumulado pelos docentes em suas respectivas áreas de especialidade ou dedicação profissional. A perspectiva tradicional do ensino na educação superior desconhece as estratégias didático-pedagógicas ou modos de ensinar problematizadores, construtivistas ou com protagonismo ativo dos estudantes, ignorando a acumulação existente na educação relativamente à construção das aprendizagens e acerca da produção e circulação de saberes na contemporaneidade 4 .

A crítica acerca do projeto hegemônico de formação nas profissões de saúde vem se acumulando há muitos anos, desde as organizações docentes, estudantis e de participação popular. Em várias carreiras, constituíram-se movimentos organizados de docentes e estudantes em busca e produção de melhores cami- nhos e estratégias para a inovação e transformação na orientação e na organização dos cursos. Quando do debate sobre as Diretrizes Curriculares Nacionais, as profissões da área de saúde mobilizaram-se de maneira expressiva. Concordando inteiramente com a ruptura ao modelo de currículo mínimo obrigatório para as carreiras, os movimentos de mudança na graduação buscavam que a noção de diretrizes indicasse como possibilidade a desejável perspectiva transformadora da formação de profissionais de saúde 5 .

Aprovadas, em sua maioria, entre 2001 e 2002 as diretrizes curriculares nacionais dos cursos de graduação em saúde (exceto Medicina Veterinária, Psicologia, Educação Física e Serviço Social) afirmaram que a formação do profissional de saúde deve contemplar o sistema de saúde vigente no país, o trabalho em equipe e a atenção integral à saúde (formação de biomédicos, fisioterapeutas, fonoaudiólogos, médicos, odontólogos e terapeutas ocupacionais). Reafirmando a posição de orientação ao sistema de saúde vigente, algumas profissões destacaram o SUS. É o caso da formação de farmacêuticos, em que constou o aposto com ênfase no SUS, e da formação de nutricionistas e de enfermeiros, nas quais constou ainda que a formação do profissional deve atender às necessidades sociais da saúde, com ênfase no SUS. Na profissão de enfermeiros constou o acréscimo de que o atendimento às necessidades sociais de saúde deve ser assegurado pela integralidade da atenção e pela qualidade e humanização do atendimento 6 .

As diretrizes curriculares, no entanto, constituem-se apenas em uma indicação, uma recomendação, já que, no Brasil, as universidades gozam de autonomia. A autonomia universitária é definida na Lei de Diretrizes e Bases da Educação Nacional (LDB) como prerrogativa de criação, expansão, modificação e extinção de cursos e programas de educação superior; fixação dos currículos de seus cursos e programas; planificação e programação de pesquisa científica e de atividades de extensão, além da elaboração da programação dos cursos 2 .

O entendimento da autonomia universitária tem exorbitado de seus limites diante da natureza pública ou de responsabilidade social da educação das novas gerações profissionais do país. A universidade não pode ser independente da regulação e direção política do Estado, e é papel dos governos, particularmente do governo federal, desenvolver políticas que induzam explicitamente as universidades ao cumprimento de seu papel social. A universidade exerce um mandato público, socialmente ou- 
torgado, e não uma soberania acadêmica como se a formação profissional superior, a produção de conhecimento, a produção científica e tecnológica ou a promoção da informação, da arte e da cultura pudessem ser independentes dos interesses da sociedade ou da sua relevância pública.

A LDB (artigo 43) firma que a educação superior deve ter entre suas finalidades o estímulo ao conhecimento dos problemas do mundo atual, destacando, em particular, os problemas nacionais e regionais, prestando serviços especializados à população e estabelecendo com a mesma uma relação de reciprocidade.

A Constituição Nacional, relativamente à educação superior, afirma que, mesmo livre à iniciativa privada, o ensino deve cumprir as normas gerais da educação nacional e a LDB coloca como atribuição da União baixar normas gerais sobre cursos de graduação e pós-graduação e o exercício de função normativa; coloca como prerrogativa do Poder Público a autorização de funcionamento das instituições de ensino e sua avaliação de qualidade, bem como afirma o respeito aos sistemas estaduais e municipais de ensino na definição de prioridades e para a melhoria da qualidade do ensino. Cabe à União, conforme a LDB, assegurar processo nacional de avaliação das instituições e dos cursos de educação superior.

Pelas prerrogativas autorizativas e normativas e pelos seus deveres de Estado, o Ministério da Educação e o Conselho Nacional de Educação impõem restrições à autonomia em temas considerados como de responsabilidade pública relevante.

A relevância pública da saúde, definida constitucionalmente, deveria ser razão suficiente para que o setor da educação considerasse haver aí campo de exceção para acoplar a autonomia universitária à gestão das políticas públicas de saúde. Além disso, considerando-se as transformações ocorridas no mundo do trabalho e da produção de conhecimento, torna-se fundamental firmar uma política pública de mudança na graduação para que as diretrizes constitucionais do SUS e as diretrizes curriculares nacionais pertençam à obediência às normas gerais da União e à observância às diretrizes gerais pertinentes ou atinentes, como prevê a LDB.

Se concebermos as políticas públicas como expressão do exercício da gestão pública de políticas de interesse social ou como resposta de governo às demandas sociais expressas por seus fóruns legítimos ou de pressão sobre a sociedade, desde o setor da educação, a mudança na graduação é parte das transformações necessárias à construção de um novo lugar so- cial à universidade brasileira. Políticas públicas no campo da avaliação (institucional, dos cursos e dos docentes), para as linhas de financiamento e apoio ao desenvolvimento universitário institucional e para a produção de conhecimento - exemplos pertinentes - são potenciais indutoras de transformação na orientação e na organização do ensino de graduação para que se cumpram as diretrizes curriculares nacionais e diretrizes constitucionais do SUS, ampliando a responsabilidade social e a capacidade de resposta e oferta da universidade aos problemas e demandas contemporâneas.

No caso da saúde, o perfil de formação dos profissionais, sua capacidade de oferecer atenção integral - fundamental para a conquista da integralidade na atenção à saúde - como de resto, as diretrizes constitucionais do SUS devem ser tomadas como determinantes na formulação da política do SUS para a mudança na graduação, uma vez que essa é uma exigência clara das lutas nacionais por saúde consolidadas nas Conferências Nacionais de Saúde realizadas no bojo da reforma sanitária brasileira 7 , sendo uma exigência do direito à saúde.

\section{Integralidade da atenção à saúde e exigência ético-política de mudança na graduação}

Marcada pela reflexão crítica e pela formulação de recomendações políticas dos gestores e conselheiros de saúde, a formação para o setor passou a ser novo objeto para a gestão do ensino. Simultaneamente às lutas pela reforma sanitária, foram se acumulando ações propositivas no campo da formação e desenvolvimento dos trabalhadores, convertendo-se as mesmas em movimentos sociais de mudança na educação dos profissionais de saúde. A existência desses movimentos, que ativamente buscaram comprometer os atores da saúde com esse debate, culminou com o engajamento do Conselho Nacional de Saúde na disputa pela mudança dos perfis profissionais e com importante mobilização, fundamental para que a definição das novas diretrizes curriculares nacionais correspondesse às necessidades reconhecidas como relevantes ao SUS e à população 4 .

As peculiaridades da saúde são muitas, além do histórico de acúmulos e de conquistas legais, vive-se um momento de profunda revisão de valores nos conhecimentos e tecnologias da atenção, de importante revisão da clínica para uma abordagem mais complexa e coerente com o andar da vida individual e coletiva, de acelerada renovação tecnológica - em proces- 
sos e instrumentos - e de pressão pelo atendimento às necessidades sociais por saúde com as dimensões brasileiras de diversidade epidemiológica, demográfica, cultural, social e econômica.

Todas as universidades e outras instituições formadoras vêm sendo pressionadas por mudanças no processo de formação e na maneira como a universidade se relaciona com a sociedade. A necessidade de mudança decorre de elementos tais como as novas modalidades de organização do mundo do trabalho em saúde e as exigências em relação ao perfil dos novos profissionais, os desafios da transdisciplinaridade na produção de conhecimento ou a necessidade de a universidade reconstruir seu papel social considerando a multiplicidade de lugares produtores do conhecimento no mundo atual 8 .

Merhy 9 nos faz entender, desde a preocupação com a lógica da produção dos atos de saúde sem ação integralizada e unificada entorno dos usuários, que essa é uma conformação tecnológica da atenção resultante de forças sociais em disputa. $\mathrm{O}$ autor nos mostra que os $\mathrm{mo}$ dos tecnológicos de atuar em saúde estão sempre implicados social e politicamente em determinados agrupamentos de força que têm interesses específicos no que se está produzindo no setor da saúde. Segundo o autor, cada conformação tecnológica impõe suas finalidades nos processos de produção. O modelo médico-hegemônico, por exemplo, expressa um grupo de interesses sociais que desenham um certo modo tecnológico de operar a produção dos atos em saúde, que empobrece ou mesmo anula a dimensão da integralidade, subjugando a clínica à baixa interação com os usuários, bem como à menor produção de autonomia dos mesmos, além da submissão dos processos decisórios sobre a organização do sistema de saúde à busca da padronização do processo saúde-doença, da focalização das intervenções e do arranjo entre cestas de ações básicas de saúde e serviços tecnológicos altamente especializados que fragmentam as populações sob assistência, os cuidados a serem assegurados, os padrões de acesso aos serviços e tecnologias, as práticas multiprofissionais, os estágios de adoecimento, as fases do horizonte clínico e tudo o mais que compete contra a integralidade.

Na área da saúde, esse debate já ocorre há muitos anos, e novos conceitos e práticas ganham vigência. Na área do ensino, as novas Diretrizes Curriculares Nacionais foram um importante passo para assinalar, como política, a necessidade de produzir mudanças no processo de formação, já que indicam um caminho, flexibilizam as regras para a organização de cur- sos e favorecem a construção de maiores compromissos da universidade com o SUS.

A mobilização do setor da saúde para a definição das diretrizes curriculares nacionais correspondeu à preocupação com a consolidação do SUS, mas também correspondeu ao esforço intelectual de romper definitivamente com o paradigma biologicista e medicalizante, hospitalocêntrico e procedimento-centrado, atendendo aos novos desafios da contemporaneidade na produção de conhecimentos e na produção das profissões. Correspondeu, igualmente, ao engajamento pela melhor aplicação da LDB, tendo em vista a relevância social das instituições formadoras e sua capacidade de dar resposta às necessidades e direitos da população e viabilizar a melhor formação inicial para a absorção dos profissionais no sistema de saúde. A melhor formação inicial para a absorção dos profissionais no sistema de saúde aparece na LDB (artigo 43) como a formação de diplomados aptos para a inserção profissional.

O movimento de mudanças da educação dos profissionais de saúde, as Diretrizes Curriculares Nacionais e as diretrizes do SUS colocam como perspectiva a existência de instituições formadoras com relevância social; o que quer dizer escolas capazes de formar profissionais de qualidade, conectados às necessidades de saúde; escolas comprometidas com a construção do SUS, capazes de produzir conhecimento relevante para a realidade de saúde em suas diferentes áreas, ativas participantes do processo de educação permanente dos profissionais de saúde e prestadoras de serviços relevantes e de boa qualidade. O movimento de mudanças identifica já há algum tempo a necessidade de políticas articuladas entre educação e saúde para criar um cenário mais favorável às mudanças que devem ser construídas nas escolas em articulação com o sistema de saúde e o controle social 10.

A articulação entre a educação superior e o sistema de saúde deve perscrutar o conceito, as diretrizes e os objetivos do SUS, tal como constam na Constituição Nacional, na Lei Orgânica da Saúde 3,11 e nas diretrizes curriculares nacionais para a grande área da saúde. Como a vinculação entre educação, trabalho e práticas sociais deve ser meta da educação superior, as Diretrizes Curriculares Nacionais e as diretrizes do SUS constituem-se em referência para propor o perfil profissional a ser formado, as oportunidades e os fatores de exposição à aprendizagem, o projeto político-pedagógico, a organização e a orientação do currículo e das práticas de ensino, a produção de conhecimento e as relações estabelecidas pela escola com o sistema de saúde local. 
No entanto, novos passos, para além das diretrizes, serão necessários para que as mudanças na formação ocorram amplamente nas graduações em saúde. Reconhecer a necessidade da transformação, trilhar novos caminhos conceituais e explorar práticas inovadoras são elementos indispensáveis, mas não suficientes para superar conceitos e práticas hegemônicos, solidamente instalados dentro e fora das instituições formadoras.

Nessa perspectiva, políticas claras do SUS, pautadas por suas diretrizes, devem indicar ações orientadas para a mudança na formação dos profissionais. Uma política para a mudança tem, necessariamente, que ser capaz de ir além das declarações de intenção e da existência formal de propostas, instâncias ou estruturas. Tem de ser capaz de convocar o pensamento crítico e o compromisso de todos os atores (docentes, estudantes, gestores de saúde e de educação, conselheiros de saúde e movimentos sociais), além de oferecer possibilidades de interferência real no processo de formação profissional.

Uma política do SUS para a mudança da formação deve necessariamente ter em conta todos os elementos que são indispensáveis para garantir o perfil de competências profissionais necessário à consolidação do sistema de saúde. Na medida que se assume o compromisso de conferir aos profissionais a potencialidade da abordagem integral à saúde das pessoas, há compromissos e supostos em relação à construção da aprendizagem e da clínica, ao papel dos vários atores no processo de formação profissional (do ensino, da gestão setorial, dos serviços de saúde, dos campos de atuação e experiência profissional para trabalhadores de saúde e das instâncias de controle social em saúde). Há compromissos e supostos em relação ao modo como é vista a instituição educacional, seu papel, seus interlocutores e seus desafios institucionais e interinstitucionais, sobretudo no que diz respeito às práticas de ensino, às práticas de saúde e às propostas relativas à produção do conhecimento.

Uma política do SUS para a mudança na formação, portanto, terá que ser capaz de captar e valorizar o processo e os movimentos em direção à transformação institucional que as escolas estiverem realizando e o concurso dos gestores de saúde em políticas de formação e desenvolvimento de trabalhadores pela aproximação com o ensino de graduação nas instituições formadoras. Pinheiro \& Luz 12 provocamnos a compreender que é no campo das práticas que as transformações se fazem necessárias. Não se trataria, seguindo essa formulação, de mudar o currículo ou mudar a organização dos serviços, senão as próprias práticas.

Algumas experiências de mudança na formação de profissionais de saúde revelam que o mais potente eixo integrador dos processos educativos (que possibilita articular conteúdos e campos disciplinares distintos, incluindo as contribuições da área social) são as práticas profissionais organizadas a partir das necessidades de saúde da população 13 .

Schaedler 14 lembra que a legislação do SUS exige novas práticas e que essas não se fazem sem novas práticas pedagógicas na formação dos profissionais, na educação em saúde, na produção de conhecimento, na educação permanente e na prestação de serviços. Desenha uma perspectiva na qual novas práticas pedagógicas multiplicam não facilitadores, mas possibilidades à educação, resultantes de uma ruptura com os modelos únicos por múltiplos modos (práticas). Para a autora, a pergunta às propostas instituídas é de que forma se pode pensá-las e organizá-las num eixo de integralidade?

Se, pelas diretrizes constitucionais, a integralidade deve se portar como eixo norteador da atenção à saúde, por que não, também como eixo da gestão setorial e da formação dos profissionais de saúde, permitindo a transformação do projeto educativo e o surgimento de novas práticas pedagógicas e inovadoras estratégias de ensino-aprendizagem?

O mais profícuo diálogo das universidades/ instituições formadoras com a rede de gestão da política e da atenção de saúde, bem como com os órgãos de controle social em saúde deveria sustentar as estratégias de mudança. Do ponto de vista do conhecimento, não é na estrutura formal que encontramos a qualidade, mas nas suas operações, interações, desafios e oportunidades.

\section{Mudança na graduação em saúde como política pública do SUS}

Durante a Assembléia Nacional Constituinte e, depois, na definição da Lei Orgânica da Saúde, foi a mobilização de amplos setores sociais que garantiu a inscrição em lei dos princípios e diretrizes para a organização de um novo sistema de saúde no país. Apesar do cenário nacional em geral desfavorável às políticas sociais, foi possível dar continuidade ao processo de reforma sanitária, havendo ampliação da cobertura dos serviços e das ações sanitárias; aumento da presença do setor público em todas as esferas de atuação, da prevenção à reabilita- 
ção; ampliação dos investimentos na área e a definição em lei de percentuais ou montantes mínimos de recursos financeiros a serem empregados no setor.

Foi possível também avançar na descentralização da gestão setorial, na criação de instâncias para negociação e pactuação entre as diversas esferas de governo e de instâncias para o controle da sociedade sobre o sistema de saúde. Houve aumento significativo dos postos de trabalho para as profissões desse campo, políticas de interiorização dos trabalhadores de saúde e recomposição dos desenhos organizativos da atenção que implicaram mudanças nas expectativas de impacto sobre os indicadores de saúde com valorização das ações de promoção e acompanhamento do processo saúdedoença nas mesmas bases territoriais em que cada usuário ou família vive e não mais notabilizando apenas os resultados hospitalares diante dos processos de adoecimento e morte.

São muitas as conquistas do ponto de vista do compromisso social construído, da democratização das estruturas do Estado, do acesso ampliado às ações e aos serviços de caráter não hospitalar e mais próximo dos territórios de moradia das pessoas e famílias (a atenção básica à saúde). No entanto, é ainda longo o caminho a percorrer para chegarmos a um sistema capaz de garantir à nossa população a oferta de atenção integral e de elevada qualidade assistencial.

Mattos 15 chama-nos a atenção para o fato de que a disputa pela reforma sanitária brasileira produziu um dos sentidos, este gravado em lei, para a integralidade: a não aceitação de uma política voltada para a oferta de serviços assistenciais descompromissada com as conseqüências dessa oferta sobre o perfil epidemiológico da população, bem como a não aceitação do ordenamento de um sistema descontextualizado das nascentes de sentido nas necessidades e problemas de saúde das pessoas e da população. Apenas com assistência não seria possível reduzir a magnitude da maioria das doenças: assistiu-se, na disputa pela reforma sanitária, a recusa ao pensamento de que políticas de atenção exclusivamente assistenciais poderiam melhorar a situação da saúde. Destacavase a importância da formulação de políticas de saúde e não apenas os dispositivos de coordenação e gestão do sistema de serviços. Por isso, a configuração desejada ao SUS deveria envolver o arranjo das instituições/instâncias de formulação das políticas de saúde e de condução da implementação dessas políticas.

Uma vez que o campo das práticas e o da formação não se dissociam, no mínimo pela medida que um oferece ao outro como território de possibilidades, um dos elementos críticos e de absoluta importância ou relevância para a construção do SUS tem sido a inadequação da formação inicial de seus profissionais (a formação no âmbito da graduação) ante as necessidades sociais de saúde e a ausência de formulação de políticas públicas do setor da saúde que efetivamente dialoguem com a possibilidade de mudança dessa formação 10 .

Merhy 9 ressalta que, se observarmos o sistema de saúde, segundo o ponto de vista dos usuários, o conjunto dos serviços, públicos ou privados, com raras exceções, não é adequado para resolver os problemas vividos, tanto os individuais como os coletivos. Se o tema saúde é dos mais citados entre os aspectos fundamentais na preservação e promoção da qualidade de vida, quando se olha a presença do tema na mídia, também se percebe, afirma o autor, o registro de que é na área de prestação de serviços que o cidadão se sente mais desprotegido. O que se mostra paradoxal, segundo a análise de Merhy, é que - se não há raridade de estudos e reportagens revelando os avanços científicos no plano do conhecimento ou das soluções em torno dos problemas de saúde que afetam as pessoas ou as populações, bem como há existência de serviços altamente equipados para suas intervenções; então que prejuízo à proteção de saúde seria esse que não encontra justificativa na falta de conhecimentos tecnológicos e nem na possibilidade de atuar sobre os problemas? Sob o ponto de vista do usuário, o autor revela não haver reclamação quanto a uma eventual falta de conhecimento tecnológico no seu atendimento, mas falta de interesse e responsabilização dos diferentes serviços à sua pessoa e ao seu problema em particular. Os usuários se sentiriam, segundo reportam, inseguros, desinformados, desamparados, desprotegidos, desrespeitados, desprezados.

Em lugar da integralidade da atenção, estaria, segundo Camargo Jr. 16, a medicalização e para mudar essa realidade seria necessário compreender o concurso de outras competências técnicas e mesmo de sabres não-profissionais, reconhecer os limites de cada fronteira técnica e compreender de maneira ampliada os determinantes do processo saúde-doença. Seriam necessárias, para o autor, mudanças na organização dos serviços e na própria formação profissional, no mínimo. Camargo Jr., então, propõe que a integralidade seja tomada como um ideal regulador. Não se tratando de impor um conceito ou um modelo para a atenção ou para a formação, a integralidade poderia estar para as práticas de saúde e de ensino da saúde, 
assim como a objetividade está para a investigação científica, impossível de ser plenamente atingida, mas uma busca de aproximação constante.

A integralidade da atenção supõe, entre outros, a ampliação e o desenvolvimento da $d i$ mensão cuidadora na prática dos profissionais de saúde, o que lhes possibilita tornar-se mais responsáveis pelos resultados das ações de atenção à saúde 9 e mais capazes de acolher, estabelecer vínculos e dialogar com outras dimensões do processo saúde-doença não inscritos no âmbito da epidemiologia e da clínica tradicionais 17.

Para a Norma Operacional Básica sobre Recursos Humanos do SUS (NOB/RH-SUS), instrumento originário do Conselho Nacional de Saúde e consolidado pela 11a Conferência Nacional de Saúde, o setor requer a formação de pessoal específico, que disponha do domínio tanto de tecnologias para a atenção individual de saúde, como para a saúde coletiva. Para a NOB/RH-SUS, a qualidade da atenção à saúde está relacionada com a formação dos profissionais, e a formulação de políticas está relacionada com a proposição de propostas de formação de novos perfis profissionais. Por isso, para a NOB/RH-SUS, tornou-se imprescindível e obrigatório o comprometimento das instituições de ensino em todos os níveis, desde o ensino fundamental, com o SUS e seu projeto tecnoassistencial (conforme definido pela legislação pertinente).

Segundo esse instrumento, diretrizes curriculares para a formação deveriam contemplar as prioridades expressas pelo perfil epidemiológico e demográfico das várias regiões do país; dever-se-ia implementar uma política de formação de docentes orientada para o SUS; formar gestores capazes de romper com os atuais paradigmas de gestão e garantir recursos para dar andamento ao ensino, à pesquisa e à extensão.

\section{Mudança na graduação em saúde como política pública do SUS e como proposição de governo na saúde}

Um outro ideário muitas vezes presente no debate sobre a mudança na formação é o da compreensão da integralidade como totalidade, o mesmo que coloca a possibilidade de uma reversão curricular tal que haveria um curso capaz de formar um generalista plenamente capacitado para a clínica integral. Merhy 18, quando aponta para a construção de um novo entendimento conceitual sobre o trabalho em saúde, mostra a oferta do modelo médico de fa- mília como uma panacéia que a tudo viria resolver, como um milagreiro, desprezando-se $a$ complexidade do atuar em saúde e a necessária multidisciplinaridade desse agir. Camargo Jr. 16 sugere que a contrapartida dessa confusão de integralidade com totalidade é o risco de um grau de controle sem precedentes, de perda de autonomia, uma medicalização também integral. $\mathrm{O}$ autor lembra que se alguns problemas merecem, de fato, a atenção médica, outros problemas podem, tranqüilamente, ser enfrentados com os recursos à mão, além de posicionar-se pela compreensão de que, isoladamente ou mesmo em categorias profissionais inteiras, somos limitados para dar conta, de fato, do espectro de demandas apresentadas nas situações de adoecimento ou sofrimento por problemas de saúde.

Feuerwerker 4 indica que a possibilidade de atenção integral implica ampliação dos referenciais com que cada profissional de saúde trabalha na construção de seu repertório de compreensão e ação e, ao mesmo tempo, o reconhecimento da limitação da ação uniprofissional para dar conta das necessidades de saúde de indivíduos e populações. Destaca que a atenção integral implica mudanças nas relações de poder entre profissionais de saúde (para que efetivamente constituam uma equipe multiprofissional) e entre profissionais de saúde e usuários (para que se amplie efetivamente sua autonomia).

Essa compreensão coloca o trabalho interdisciplinar e multiprofissional como necessidade fundamental e uma estratégia mais exeqüível e desejável do que a tentativa de criar superprofissionais de saúde, formar profissionais competentes para o atendimento de toda e qualquer necessidade dos usuários, mesmo as não percebidas.

O objeto da mudança na formação, desde o lugar formulador de políticas do SUS, pode ou deve ser relativo à orientação dos cursos e não aos processos de ordenamento do ensino no interior da organização didático-curricular, tarefa mais própria da gestão do ensino que da gestão em saúde. A tarefa da gestão em saúde para a mudança na formação deve ter como objetivo o engendramento de novas relações de compromisso e responsabilidade entre a universidade e o SUS, de modo a possibilitar a compatibilidade de perfis profissionais, de produção de conhecimento e de prestação de serviços, cooperação e assessoramento.

O projeto de formação de cada curso da área da saúde, em cada tempo dado, será sempre o resultado de uma dada conformação tecnológica que se expressa nos serviços de atenção, 
na lógica de gestão do sistema de saúde, na participação promovida aos usuários, na gestão dos processos de ensino e nas práticas pedagógicas. A mudança das práticas antiintegralidade não se dará pela reconfiguração conteúdo-curricular, simplesmente metodológica ou pela introdução pontual de fatores de exposição à aprendizagem, ainda que os desenhos curriculares hegemônicos, organizados segundo o paradigma biologiscista, sejam indiscutivelmente obstaculizadores de outros padrões de pensamento clínico e de perfis SUS-implicados. A ênfase nos aspectos biológicos, a perspectiva fragmentada e fragmentadora e a hierarquização implícita de saberes, segundo Camargo Jr. 16, são quase que programaticamente opostas àquelas idéias que podem ser agregadas sob um rótulo de integralidade.

As relações de compromisso e responsabilidade entre o SUS e as instituições de educação superior, se requerem políticas, incluem proposições de governo. Para a viabilização da política, serão indicações a um projeto de governo:

- a atividade de implementação das diretrizes curriculares nacionais para as carreiras da saúde;

- a previsão ativa de participação conjunta em projetos locorregionais de educação permanente para docentes e profissionais em serviço;

- o estabelecimento de projetos de cooperação técnica para o desenvolvimento de capacidades e competências pedagógicas à rede de serviços e gestão local em saúde, para apoiar o provimento e a fixação de profissionais e a qualificação da gestão local e locorregional do SUS; - a produção de conhecimento científico e tecnológico relevante para a consolidação e avanço do SUS;

- a construção de saberes, informações e tecnologias relativas ao cuidado tecnoassistencial e às relações de cuidado;

- a construção do ensino de saúde de maneira articulada e negociada com o SUS.

Como proposição de governo, uma política de mudança na formação deve possibilitar o fortalecimento da articulação entre a universidade e os serviços/sistema de saúde de modo a ampliar as chances de indução de novos compromissos de cooperação entre universidade e SUS, desde a base locorregional de inserção da instituição formadora, dos órgãos de gestão do SUS e de sua rede de atenção. Esse processo de aproximação e construção de compromissos, sem dúvida, favorece a ampliação da responsabilidade pública e da relevância social da universidade na medida em que traz para o cenário da educação o conjunto das referências centrais da reforma sanitária brasileira ou das di- retrizes do SUS: descentralização da gestão, integralidade da atenção e fortalecimento do controle da sociedade sobre as ações, serviços e sistema de saúde.

\section{Considerações finais}

Considerando que o processo saúde-doença é um fenômeno complexo e não restrito ao campo biológico, somente sendo tratado de maneira integral é que poderá ser adequadamente abordado. Para tanto, além de ampliar a base conceitual da ação de cada profissional, é necessária a configuração de equipes para a ação multiprofissional, buscando a maior potência de cada ação.

Assim como o cientificismo varreu para a esfera privada toda a dimensão subjetiva do mundo, o ensino, na modernidade, desqualificou, nas práticas de saúde, as ferramentas vistas como não científicas, invertendo prioridades: preferindo a doença ao doente, fragmentando o todo, reduzindo o indivíduo a um somatório de órgãos e sistemas, ignorando tanto sua especificidade biológica, como suas dimensões psicológicas, culturais e sociais 4 . Convivemos com a necessidade de transformar os conceitos e as práticas de saúde que orientam o processo de formação para produzir profissionais capazes de compreensão e ação relativas à integralidade nas práticas em saúde.

Ainda que o crescimento científico e tecnológico no setor da saúde nos apresente o desenvolvimento de formas sofisticadas de prevenção e tratamento das doenças e medidas verdadeiramente efetivas de intervenção ordenadas em práticas gerenciadas por serviços de saúde e equipes multiprofissionais, não podemos confiar nas mais refinadas tecnologias sem escutar a vida concreta e cotidiana, como individualmente vivida, daqueles que vêm aos serviços e às equipes de saúde 19. Não é possível a renitência na inscrição corporal da doença, na qual os doentes só são objeto de saber na medida em que se constituem no terreno em que a doença evolui 20 . Schaedler 14 cunhou o termo doençocentrada para as práticas de saúde que se negam à integralidade, afirmando que, mesmo diante da prevenção e promoção em saúde, o usuário é apenas o território da doença e não a pessoa a ser acompanhada. A expressão proposta nos permite destacar que acompanham os quadros mórbidos ou o comportamento do processo saúde-doença e não pessoas, grupos sociais, histórias de vida, histórias familiares, histórias culturais ou mesmo o andar da vida diante de adoecimentos, sofrimentos ou a sim- 
ples demanda por orientação e informação sobre o cuidado em saúde.

Numa perspectiva de integralidade, o desenvolvimento da atenção se dirige à produção da saúde e não só ao tratamento 21 . Como coloca Campos 22, a prática da saúde envolve compromisso ético com a reprodução da vida, que os próprios profissionais supõem ser a razão principal do trabalho em saúde. A atitude ética de reprodução da vida não recorta radicalmente de seu objeto de trabalho qualquer das dimensões da realidade constitutiva da singularidade; para o autor: natural-biológica, subjetivo-psicológica e valorativa-social, colocando a integralidade como exigência ético-política do trabalho em saúde. Um desafio, ainda à integralidade, colocado por Ceccim 19 , ao referir-se à assistência na internação hospitalar em pediatria, é o da escuta à dimensão vivencial da experiência de ser saudável-adoecer-curar-se, que não se esgota na melhor qualidade do diagnóstico e prescrição, tampouco com a simples agregação da noção de realidade cultural e simbólica. A dimensão vivencial é relativa às condições subjetivas da produção da existência e nos conta das expectativas de cura, sobrevida, qualidade de vida afetiva, de retorno aos padrões de convivência anteriores e continuidade dos laços com o cotidiano, por isso deve ser tomada como demanda às práticas da integralidade.

Quanto maiores os índices de interdisciplinaridade e maiores as pactuações interinstitucionais, quanto mais diversificados os cenários de aprendizagem e os fatores de exposição dos alunos (não mais somente o professor, o livro, a pessoa internada ou no ambulatório-escola), maior a instauração de possibilidades à integralidade das práticas em saúde 8,13 .

Trata-se, então, de enfocar que a saúde, por ser encontro, produz afetos, nossa atenção clínica não será adequada sem o mínimo de escuta aos fluxos de vida na experiência concreta dos adoecimentos ou demandas por atenção de saúde 19,22. Trata-se, também, de enfocar os fluxos e atravessamentos institucionais entre modos de cuidar/tratar e modos de ensinar na construção da mudança na formação. As questões de gestão colegiada, de multiprofissionalidade e de alteridade, então, se colocam em oposição à formação medicalizada e procedimento-centrada e ao especialismo. É nossa tarefa reverter as teorias biologicistas da educação na saúde para uma teoria da integralidade na educação dos profissionais de saúde.

O desafio de propor a mudança na graduação das profissões de saúde sob o eixo da integralidade nos mostrou que é possível formular uma política de saúde específica para a formação. Igualmente, começamos a detectar que é possível e necessária uma teoria da mudança na graduação em saúde que dialogue e se construa desde a gestão setorial. Precisamos, como sociedade ou como setor de formulação de políticas públicas, aprender a formular políticas com significado na vida da população, nas tarefas de gestão setorial, na organização das práticas de atenção e na transformação da educação superior em saúde. Se precisamos aprender a formular políticas, também precisamos, os gestores do SUS, aprender a cuidar das políticas: observar comportamentos, acompanhar processos, oferecer assessoramento, disponibilizar informação, abrir-se para as mutações de sentido e ordenamento gerencial etc. Os compromissos com o eixo da integralidade na mudança da graduação em saúde virão dos vários atores que com ela se comprometerem, principalmente aqueles que estão nas interfaces da formação: docentes, dirigentes de ensino, estudantes, gestores de educação e gestores do SUS.

O governo brasileiro tem, neste momento, essa base político-conceitual na sustentação de suas intervenções como formulador de uma política de educação para o SUS, estando essa política orientada para a produção de mudanças tanto nas práticas de atenção e gestão como de formação em saúde.

\section{Resumo}

O artigo argumenta a legitimidade legal, técnica e política para a formulação de uma política de Estado com o objetivo de ordenar a formação de profissionais em consonância com as necessidades de saúde da população e destaca as competências do setor da educação e do setor da saúde nessa construção. A integralidade é tomada como eixo para propor e apoiar as necessárias mudanças na formação de profissionais, já que implica uma compreensão ampliada da saúde, a articulação de saberes e práticas multiprofissionais e interdisciplinares e a alteridade com os usuários para a inovação das práticas em todos os cenários de atenção à saúde e de gestão setorial.

Atenção Integral à Saúde; Prática Profissional; Política de Saúde 


\section{Colaboradores}

R. B. Ceccim organizou o ensaio, que teve a contribuição de L. C. M. Feuerwerker.

\section{Referências}

1. Brasil. Constituição da República Federativa do Brasil. Brasília: Senado Federal; 1988.

2. Brasil. Lei no 9.394. Estabelece as diretrizes e bases da educação nacional. Diário Oficial da União 1996; 20 dez.

3. Brasil. Lei no 8.080. Dispõe sobre as condições para a promoção, proteção e recuperação da saúde, a organização e o funcionamento dos serviços correspondentes e dá outras providências. Diário Oficial da União 1990; 19 set.

4. Feuerwerker LCM. Além do discurso da mudança na educação médica: processos e resultados. São Paulo: Editora Hucitec/Londrina: Rede Unida/ Rio de Janeiro: Associação Brasileira de Educação Médica; 2002.

5. Rede Unida. Sobre a proposta de diretrizes curriculares para a medicina. Olho Mágico 1999; 5:11-3.

6. Almeida M, organizador. Diretrizes curriculares nacionais para os cursos universitários da área da saúde. Londrina: Rede Unida; 2003.

7. Ceccim RB, Armani TB, Rocha CMF. O que dizem a legislação e o controle social em saúde sobre a formação de recursos humanos e o papel dos gestores públicos, no Brasil. Ciênc Saúde Coletiva 2002; 7:373-83.

8. Feuerwerker LCM, Sena RR. A construção de novos modelos acadêmicos, de atenção à saúde e de participação social. In: Feuerwerker L, Almeida M, Llanos CM, organizadores. A educação dos profissionais de saúde na América Latina: teoria e prática de um movimento de mudança. Tomo 1 - Um olhar analítico. São Paulo: Editora Hucitec/ Buenos Aires: Lugar Editorial/Londrina: Editora UEL; 1999. p. 47-81.

9. Merhy EE. A perda da dimensão cuidadora na produção da saúde - uma discussão do modelo assistencial e da intervenção no seu modo de trabalhar a assistência. In: Campos CR, Malta DC, Reis AT, Santos AF, Merhy EE, organizadores. Sistema Único de Saúde em Belo Horizonte: reescrevendo o público. São Paulo: Xamã; 1998. p. 103-20.

10. Feuerwerker LCM. Estratégias para a mudança da formação dos profissionais de saúde. Caderno de Currículo e Ensino 2001; 2:11-23.

11. Brasil. Lei no 8.142. Dispõe sobre a participação da comunidade na gestão do Sistema Único de Saúde (SUS) e sobre as transferências intergovernamentais de recursos financeiros na área da saúde e dá outras providências. Diário Oficial da União 1990; 28 set.
12. Pinheiro R, Luz MT. Práticas eficazes $x$ modelos ideais: ação e pensamento na construção da integralidade. In: Pinheiro R, Mattos RA, organizadores. Construção da integralidade: cotidiano, saberes e práticas em saúde. Rio de Janeiro: Instituto de Medicina Social, Universidade do Estado do Rio de Janeiro/ABRASCO; 2003. p. 7-34.

13. Feuerwerker LCM. Reflexões sobre as experiências de mudança na formação dos profissionais de saúde. Olho Mágico 2003; 10:21-6.

14. Schaedler LI. Pedagogia cartográfica: a estética das redes no setor da saúde como política cognitiva e ética do ensino-aprendizagem em coletivos [Dissertação de Mestrado]. Porto Alegre: Programa de Pós-Graduação em Educação, Universidade Federal do Rio Grande do Sul; 2003.

15. Mattos RA. Integralidade e a formulação de políticas específicas de saúde. In: Pinheiro R, Mattos RA, organizadores. Construção da integralidade: cotidiano, saberes e práticas em saúde. Rio de Janeiro: Instituto de Medicina Social, Universidade do Estado do Rio de Janeiro/ABRASCO; 2003. p. 45-60.

16. Camargo Jr. KR. Um ensaio sobre a (in)definição de integralidade. In: Pinheiro R, Mattos RA, organizadores. Construção da integralidade: cotidiano, saberes e práticas em saúde. Rio de Janeiro: Instituto de Medicina Social, Universidade do Estado do Rio de Janeiro/ABRASCO; 2003. p. 35-44.

17. Campos GWS. Considerações sobre a arte e ciência da mudança: revolução e reforma. O caso da saúde. In: Cecílio LCO, organizador. Inventando a mudança na saúde. São Paulo: Editora Hucitec; 1994. p. 29-86.

18. Merhy EE. Saúde: a cartografia do trabalho vivo. São Paulo: Editora Hucitec; 2002.

19. Ceccim RB. Criança hospitalizada: a atenção integral como uma escuta à vida. In: Ceccim RB, Carvalho PRA, organizadores. Criança hospitalizada: atenção integral como escuta à vida. Porto Alegre: Editora da Universidade; 1997. p. 27-41.

20. Clavreul J. A ordem médica: poder e impotência do discurso médico. São Paulo: Brasiliense; 1988.

21. Ceccim RB. Diversidade e adversidade na prática da atenção à saúde. Saúde - Revista do NIPESC 1998/1999; 3/4:59-77.

22. Campos GWS. A ética e os trabalhadores de saúde. Saúde em Debate 1994; 43:60-3.

Recebido em 14/Jun/2004

Aprovado em 15/Jun/2004 